Original Research

\title{
A Normative Behavior of Pre-Travel Health Consultation and the Associated Factors among Travelers
}

\section{Gede Nova Ariawan, Kadek Eka Swedarma, Ni Putu Emy Darma Yanti}

School of Nursing Faculty of Medicine Udayana University, Bali, Indonesia

\begin{abstract}
Introduction: Travelers may transmit diseases due to their behavior of travel, consequently travelers should consider preventive measurement through pre-travel health consultation seeking behavior. Pre-travel health consultation is a particular preparation ideally conducted by international travelers to obtain risk assessment and management to prevent the transmission of diseases. This study investigates the relationship of sociodemographic characteristics and itinerary on pre-travel health consultation behavior among international travelers in Badung, Bali.
\end{abstract}

Methods: A descriptive-correlative design using a cross-sectional approach employed 125 participants determined by a purposive sampling technique performed in the ten tourist destinations of Badung Regency. Data collection was conducted on February 15th until March 5th, 2020. Data demography, travel plan, and anonymous questionnaires regarding pre-travel health consultation behavior are used in this research. The Gamma coefficient correlation and Kruskal-Wallis statistic tests were performed in the study for bivariate analysis.

Results: The results showed that age $(\mathrm{p}<0.001 ; \mathrm{r}=-0.650)$ and past-travel history to Bali ( $\mathrm{p}=0.004$; $\mathrm{r}=-0.475$ ) were significantly correlated with pretravel health consultation behavior among international travelers in Badung, Bali. Meanwhile sex, nationality, last education, travel duration, and types of the destination visited were not significantly associated with pre-travel health consultation behavior among international travelers in Badung, Bali ( $\mathrm{p}>0.05)$.

Conclusion: The age and past-travel history to Bali seem to be predictors for travelers to uptake pre-travel health consultation, thus nurses should be able to promote the implementation of pre-travel health consultation by utilizing the media promotion appropriately adjusted to the age of travelers and travel experience.

\section{ARTICLE HISTORY}

Received: August 17, 2020

Accepted: January 23, 2021

\section{KEYWORDS}

consultation; itinerary; nurse's role; travelers; travel health

\section{CONTACT}

I Gede Nova Ariawan

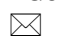

novaariawan@student.unud.ac.id $\equiv$ School of Nursing Faculty of Medicine Udayana University, Bali, Indonesia

Cite this as: Ariawan, I. G. N., Swedarma, K. E., Yanti, N. P. E. D. (2021). A Normative Behavior of Pre-Travel Health Consultation and the Associated Factors among Travelers. Jurnal Ners, 16(1). 26-34 doi:http://dx.doi.org/10.20473/jn.v16i1.21443

\section{INTRODUCTION}

International tourism has been increasing in the last decade due to the dynamic of individual mobility. It urges all aspects of human life to follow the movement. It was proved by the fact that the number of international travelers in the world has been growing steadily to around 1.1 billion in 2015 (Heywood et al., 2012). Approximately, 6.54\% growth of arrivals to Bali in 2018 were made by international travelers (Bali Government Tourism Office, 2019), which indicates the escalation of traveling among international travelers. The high number of trip intensity can affect the health of travelers and the local population in the destination country. Travelers play a significant role in transmitting travel-related infectious diseases due to the their travel pattern and behavior (Heywood et al., 2012). Masen, Yohan, Somia, Myint, and Sasmono (2018) noted $66.2 \%$ of 201 travelers were infected with dengue also 48.7\% was caused by dengue virus type 2 (DENV-2). Diarrhea or gastroenteritis, systemic febrile disease, 
respiratory tract infection, and typhoid are other diseases susceptible for travelers (Sohail et al., 2019; Sumadewi et al., 2018). Additionally, in the beginning of December 2019, a newly severe acute respiratory syndrome-coronavirus 2 (SARS-CoV 2) was discovered in China and rapidly spread around the globe (Chinazzi et al., 2020). Consequently, many governments, including Indonesia's, admitted they were unprepared to cope with the pandemic and one of the strategies was to issue travel restrictions from and to Hubei, China (Chinazzi et al., 2020; Djalante et al., 2020). It shows travelers have health risks related to travel that require preventive behavior to alleviate travel-related illnesses and they should be prepared for all possibility, such as a pandemic.

Pre-travel health consultation (PTHC) implementation with a health professional is one of the preventive measures conducted by travelers before departure. It aims to reduce health risk during the trip, by assessing health risk, itinerary, and individual characteristics, communicating the information regarding infectious diseases risk adjusted to travelers' needs and providing risk management, such as relevant vaccination of the destination (Heywood et al., 2012; Paudel et al., 2017; Zuckerman et al., 2015). The effectiveness of this program can diminish risk behavior and improve the preventive measures of infectious diseases (Al-Abri et al., 2016). Tan, St. Sauver, and Sia (2018) also reported that travelers who had travelers' diarrhea (TD) and did not uptake PTHC would be faced with prolonged hospitalization and lack of capability to comply with medication regimen while diagnosed with TD.

Travelers that engage with health behavior have the probability to be affected by several factors. Predisposition, enabling, and reinforcing factors can encourage healthy behavior (Green, 1974). Sociodemographic characteristics such as age, sex, nationality, and education level were mentioned as predisposition factors that influenced PTHC seeking behavior (Adou et al., 2019; El-Ghitany et al., 2018; Shady et al., 2015; Zhang et al., 2016), yet Shady et al. (2015) revealed that sex was not significantly correlated to visits to the travel health clinic (THC). Moreover, travel plan characteristics, including travel duration, types of travel destination visited, and pasttravel history, were noted as factors that influenced PTHC uptake behavior among travelers (GagneuxBrunon et al., 2016; Pavli et al., 2014).

Although the PTHC utilization can provide a positive impact on international travelers that influences by their sociodemographic and itinerary, previous studies found that most travelers did not seek PTHC with a health professional (Heywood et al., 2012a; LaRocque et al., 2010; Paudel et al., 2017). Those studies showed that travelers had not yet carried out this program well. Nurses play a crucial role in practicing of health promotion in the community, thus conducting an assessment regarding knowledge, attitude, and practice (KAP) regarding PTHC is one of the initial nursing processes required to do in reaching and convincing travelers to implement the community-based program, otherwise the advice of nurses and other health professionals have to compete with non-medical information sources, such as the internet and friends (Bauer et al., 2013).

KAP are behavior domains that influence travelrelated illness prevention (Omer et al., 2015). Al-Abri, Abdel-Hady, and Al-Abaidani (2016) found that most travelers had good knowledge and positive attitude regarding travel-related infectious diseases; however, only $22.5 \%$ of 204 travelers conducted PTHC. That condition describes that a good knowledge, and a positive attitude did not align with preventive behavior tangibly. Most of the previous studies investigated knowledge, attitudes, and practice regarding infectious illnesses related to travel (Adou et al., 2019; Chow et al., 2018), travel health (Al-Abri et al., 2016), and vaccination (Zhang et al., 2016). It shows that there has been no report that quantified a normative behavior of PTHC and associated factors among international travelers. This study was aimed to identify the relationship of sociodemographic and itinerary characteristics on PTHC behavior among international travelers in Badung, Bali.

\section{MATERIALS AND METHODS}

A quantitative study with descriptive-correlative design by using a cross-sectional approach was performed in the ten tourist destinations of Badung Regency, namely Sangeh Monkey Forest, Seminyak Beach, Kayu Aya Beach, Petitenget Beach, Canggu Beach, Batu Bolong Beach, Batu Belig Beach, Uluwatu Temple, Pandawa Beach, and Dreamland Beach. Data collection was conducted on February $15^{\text {th }}$ until March $5^{\text {th }}, 2020$. This study examined several variables, including age, sex, nationality, last education, travel duration, types of the destination visited, and past-travel history to Bali as independent variables, additionally PTHC behavior was the dependent variable.

The population of this study was the total number of international traveler arrivals in Badung Regency in 2018, which was $2,951,941$ arrivals. A purposive sampling technique used in this research and a minimum sample was 100 participants calculated by Slovin formula and the error tolerance level was $10 \%$ (0.1). International travelers aged $\geq 18$ years, communication with English, the traveler willing signed the informed consent were eligible as a research participant, while international travelers who lived in Bali over 12 months were excluded from this study. A total of 125 participants were enrolled in the present study.

The primary data were collected by using selfadministered and anonymous questionnaire that composed demographic data (birth of date, sex, nationality, and last education), travel plan (travel duration, types of the destination visited, and pasttravel history to Bali), and PTHC behavior. The PTHC 
behavior questionnaire comprised 20 items of statements to measure PTHC behavior normatively. The PTHC behavior questionnaire was developed by the researchers based on the literature review regarding the PTHC and encompassed: (1) The principles of PTHC; (2) Risk assessment related to the assessment of demography, itinerary, culture of travelers; (3) Risk communication associated to provides the information of the travel-related illness prevention, destination country, and vaccination adjusted to the traveler's requirement; and (4) Risk management, including administered the vaccination. It included positive and negative statements related to three indicators (KAP). The Guttman scale (true/false) was used for knowledge indicator and the Likert scale (strongly agree until strongly disagree) was used for attitude and practice indicators. The maximum score of PTHC behavior attained 68, classified into two categories of behavior: good (cut-off point median $>50$ ) and poor (cut-off point median $\leq 50$ ). The instrument was translated into English by the translator from the Language Center of the Udayana University. The validity test of the questionnaire involved 30 travelers and the resulted Cronbach's alpha values were 0.454-0.608 for the knowledge indicator, $0.422-0.830$ for the attitude indicator, and $0.478-0.751$ for the practice indicator, while the reliability test of PTHC behavior questionnaire found Cronbach's alpha value. 0.898

The researchers obtained data collection permission from the institutions. Research explanation was delivered to travelers who volunteered and informed consent was administered after declaring willing to become a research participant in the current study. Data collection was conducted by the researchers without a research assistant. Our study was appraised by the Ethical Research Commission of the Faculty of Medicine, Udayana University and Sanglah General Hospital Denpasar by the approval number: 404/UN14.2.2.VII.14/LP/2020.

The univariate analysis was conducted to describe the characteristics of sociodemography, itinerary, and PTHC behavior of the participants by displaying the distribution frequency. Our study performed a bivariate analysis by using the Gamma coefficient correlation and Kruskal-Wallis statistic tests. The bivariate analysis determined the relationship between sociodemography and itinerary characteristics on PTHC behavior. This study employed 95\% confidence interval $(\alpha=0.05)$ that was analyzed by using computer software.

\section{RESULTS}

Table 1 describes the sociodemographic characteristics of travelers, including $68 \%$ of participants were an adult category, 54.4\% were female, $78.4 \%$ were Europeans, dominated by Russian, British, Dutch, German, and French. The domination of other nationalities was also reported from the United States (America), Indian (Asia),
Australian (Oceania), and Moroccan (Africa). Most of the travelers had tertiary education (72\%). In addition, Table 1 also reports travel plan characteristics. Approximately $54.4 \%$ of travelers had short-travel ( $\leq 28$ days), $76.8 \%$ of participants visited the nature-based tourism, and $51.2 \%$ had not traveled to Bali. Table 2 also shows that most of the travelers had a poor category of PTHC behavior (54.4\%) nonetheless $45.6 \%$ of travelers had good behavior.

Table 3 shows that there was significance with a strong and negative correlation between age with PTHC behavior among international travelers in Badung, Bali ( $\mathrm{p}<0.001$; $\mathrm{r}=-0.650)$, moreover, pasttravel history to Bali also had a moderate and negative association significantly $(\mathrm{p}=0.004 ; \mathrm{r}=$ 0.475). Other sociodemography and itinerary characteristics such as sex, nationality, last education, travel duration, and types of the destination visited were not significantly associated with PTHC behavior among international travelers in Badung, Bali $(p>$ 0.05). Further analysis reports that a higher proportion of the good behavior was found among adolescent travelers compared to adult and elderly travelers. Female travelers also had a higher proportion of good behavior. Asian travelers reported a higher number of good behaviors compared to other nationalities from four continents that more likely had poor behavior. A good behavior was predominantly found among travelers who had secondary education (46.9\%); however, there was no significant difference with travelers who had tertiary education (45.6\%). A higher percentage of the good behavior was noted among travelers with shorttravel, meanwhile, travelers with long-travel more likely had poor behavior. The proportional differences were not significantly reported among travelers that visited nature or wellness-based tourism, nevertheless, a higher proportion of the good behavior was found among travelers who visited the nature-based tourism. The first-time visitors were dominated by a good category of PTHC behavior (57.8\%).

\section{DISCUSSION}

Our study evaluated PTHC behavior normatively and associated factors among international travelers in Badung, Bali. This topic is strongly relevant with the current situation in Bali because travel health is evolved by the policy makers in Bali and some health facilities have been providing travel health service. In addition, the number of tourist arrivals in Bali is growing steadily.

The finding of this study also showed that majority of the participants had a poor category of PTHC behavior. In contrast, previous studies found that travelers had a higher proportion of good knowledge $(63.2 \%)$ and positive attitude $(60.8 \%)$ toward travel health, nonetheless only $22.5 \%$ of 204 travelers received PTHC (Al-Abri et al., 2016). It indicates that the travelers are not able to demonstrate the 
Table 1. The Sociodemography and Itinerary Characteristics of International Travelers in Badung, Bali in 2020 $(\mathrm{n}=125)$

\begin{tabular}{|c|c|c|}
\hline Variables & $\mathbf{n}$ & $\%$ \\
\hline \multicolumn{3}{|l|}{ Age (year) } \\
\hline Older adolescent (17-25) & 24 & 19.2 \\
\hline Adult (26-64) & 85 & 68.0 \\
\hline Elderly ( $\geq 65)$ & 16 & 12.8 \\
\hline \multicolumn{3}{|l|}{ Sex } \\
\hline Male & 57 & 45.6 \\
\hline Female & 68 & 54.4 \\
\hline \multicolumn{3}{|l|}{ Nationality } \\
\hline European & 98 & 78.4 \\
\hline American & 11 & 8.8 \\
\hline Oceania & 9 & 7.2 \\
\hline Asian & 6 & 4.8 \\
\hline African & 1 & 0.8 \\
\hline \multicolumn{3}{|l|}{ Last Education } \\
\hline Primary education & 3 & 2.4 \\
\hline Secondary education & 32 & 25.6 \\
\hline Tertiary education & 90 & 72.0 \\
\hline \multicolumn{3}{|l|}{ Travel Duration (days) ${ }^{\mathrm{a}}$} \\
\hline Short travel ( $\leq 28$ days) & 68 & 54.4 \\
\hline Long travel (>28 days) & 57 & 45.6 \\
\hline \multicolumn{3}{|l|}{ Type of Destination Visited } \\
\hline Wellness-based tourism & 29 & 23.2 \\
\hline Nature-based tourism & 96 & 76.8 \\
\hline \multicolumn{3}{|l|}{ Past-travel History to Bali (times)a } \\
\hline First time & 64 & 51.2 \\
\hline$>1$ times & 61 & 48.8 \\
\hline
\end{tabular}

Table 2. PTHC Behavior among International Travelers in Badung, Bali in 2020 (n=125)

\begin{tabular}{|c|c|c|}
\hline Variable & $\mathbf{n}$ & $\%$ \\
\hline \multicolumn{3}{|l|}{ Pre-Travel Health Consultation Behavior } \\
\hline Poor behavior & 68 & 54.4 \\
\hline Good behavior & 57 & 45.6 \\
\hline
\end{tabular}

knowledge and positive attitude in a tangible behavior of the preventive measures because they assume that to commit with the preventive behavior, they need guidance. Notoatmodjo (2010) explained that a guided practice is an individual ability to require guidance in implementing a certain action, hence, in this stage, an individual cannot yet adopt or modify the preventive behavior in their life.

Our study also demonstrated that age had a significant and negative correlation with PTHC behavior among international travelers in Badung, Bali. It implies that the younger travelers were more likely to have a good behavior of the PTHC compared to the old group of travelers who had a poor behavior. Previous studies noted a consistent result, namely age was significantly correlated with PTHC seeking behavior (Gagneux-Brunon et al., 2016) and good knowledge regarding travel health (Chow et al., 2018). Likewise, Zhang et al. (2016) also reported that older travelers had lack of awareness of vaccinations, which plays a role in preventing disease. It showed that a negative association was found in the previous study. Conversely, Shady et al. (2015) found a different result.

The negative correlation between age and PTHC behavior could be explained because the younger travelers are more likely to have better risk perception, and this can be the protection, thus it can increase the focus to the risk and force travelers to indicate a positive attitude about hazards in the destination (El-Ghitany et al., 2018). Kwon et al. (2019) also explained that lacking compliance to the vaccination and malaria prophylaxis among adults and elderly is because they have frightened fear toward adverse effect of the vaccination, cost, they did not intend to adopt risky behavior during traveling, and had a history of past immunization.

A higher risk perception among older adolescent travelers was also reported in this study, they had the highest proportion of good category of the PTHC behavior $(83.3 \%)$. This condition revealed that younger travelers are able to apply good knowledge and positive attitude to the real practice compared to older travelers, thus it seems the difference of theory in this research, namely age-maturity, tends to encourage individuals to adopt healthy lifestyle behavior (Potter \& Perry, 2005). Age is well-known as a predisposition factor that affects behavior, the increasing age can describes the maturity in arguing and judgment (Green, 1974). Underestimating health risk, have traveling experience, and financial limitation among older travelers need to be considered; however, these are challenges for health professionals to provide the recommendation (Del Prete et al., 2019). Nurse has significant role as an educator, importantly to emphasize the 
Table 3. The Relationship of Sociodemography and Itinerary Characteristics among International Travelers in Badung. Bali in $2020(n=125)$

\begin{tabular}{|c|c|c|c|c|c|c|}
\hline \multirow{3}{*}{ Variables } & \multicolumn{4}{|c|}{ Pre-Travel Health Consultation Behavior } & \multirow{3}{*}{$\mathbf{r}$} & \multirow{3}{*}{ p-value } \\
\hline & \multicolumn{2}{|c|}{ Poor } & \multicolumn{2}{|c|}{ Good } & & \\
\hline & $\mathbf{n}$ & $\%$ & $\mathbf{n}$ & $\%$ & & \\
\hline \multicolumn{7}{|l|}{ Age } \\
\hline Older adolescent & 4 & 16.7 & 20 & 83.3 & \multirow{3}{*}{-0.650} & \multirow{3}{*}{$<0.001^{*}$} \\
\hline Adult & 52 & 61.2 & 33 & 38.8 & & \\
\hline Elderly & 12 & 75.0 & 4 & 25.0 & & \\
\hline \multicolumn{7}{|l|}{ Sex } \\
\hline Male & 34 & 59.6 & 23 & 40.4 & \multirow[t]{2}{*}{-} & \multirow[t]{2}{*}{$0.283^{* *}$} \\
\hline Female & 34 & 50.0 & 34 & 50.0 & & \\
\hline \multicolumn{7}{|l|}{ Nationality } \\
\hline European & 55 & 56.1 & 43 & 43.9 & \multirow{5}{*}{-} & \multirow{5}{*}{$0.358^{* *}$} \\
\hline American & 6 & 54.5 & 5 & 45.5 & & \\
\hline Asian & 1 & 16.7 & 5 & 83.3 & & \\
\hline Oceania & 5 & 55.6 & 4 & 44.4 & & \\
\hline African & 1 & 100.0 & 0 & 0.0 & & \\
\hline \multicolumn{7}{|l|}{ Last education } \\
\hline Primary education & 2 & 66.7 & 1 & 33.3 & \multirow{3}{*}{0.005} & \multirow{3}{*}{$0.980^{*}$} \\
\hline Secondary education & 17 & 53.1 & 15 & 46.9 & & \\
\hline Tertiary education & 49 & 54.4 & 41 & 45.6 & & \\
\hline \multicolumn{7}{|l|}{ Travel duration } \\
\hline Short travel & 32 & 47.1 & 36 & 52.9 & \multirow[t]{2}{*}{-0.317} & \multirow[t]{2}{*}{$0.067^{*}$} \\
\hline Long travel & 36 & 63.2 & 21 & 36.8 & & \\
\hline \multicolumn{7}{|l|}{ Types of destination visited } \\
\hline Wellness-based tourism & 16 & 55.2 & 13 & 44.8 & \multirow[t]{2}{*}{-} & \multirow[t]{2}{*}{$0.924^{* *}$} \\
\hline Nature-based tourism & 52 & 54.2 & 44 & 45.8 & & \\
\hline \multicolumn{7}{|l|}{ Past-travel History to Bali } \\
\hline First time & 27 & 42.2 & 37 & 57.8 & \multirow{3}{*}{-0.475} & \multirow{3}{*}{$0.004^{*}$} \\
\hline$>1$ times & 41 & 67.2 & 20 & 32.8 & & \\
\hline Total & 68 & 54.4 & 57 & 45.6 & & \\
\hline
\end{tabular}

${ }^{*}$ Gamma correlation statistic test ( $\left.\alpha=0.05\right) ;{ }^{* *}$ Kruskal-Wallis statistic test $(\alpha=0.05$ )

communication process effectively in order to administer an optimal nursing care which is influenced by language proficiency and communication of nurses (Swedarma et al., 2016).

Conversely, sex had no association significantly with PTHC behavior among international travelers in Badung, Bali. This result was consistent with previous studies, namely sex was not significantly correlated with visits the THC to conduct PTHC or seek health information (Kwon et al., 2019; Shady et al., 2015). In contrast, several studies reported that sex was significantly correlated to PTHC implementation, especially among female travelers (Chow et al., 2018; Heywood et al., 2012). This condition shows that sex is still a polemic which affects individual behavior.

Our study found that sex was not significantly associated with PTHC behavior because genderrelated stigma has been shifting which is often linked to healthy lifestyle behavior. Stigma friction was caused by various programs from the World Health Organization, such as eradication of gender stereotypes, upholding gender equality, omitting gender barriers in accessing health, moreover implementation of gender-responsive and gendertransformative (World Health Organization, 2020). Therefore, further analysis noted that good category of the PTHC behavior is more likely found among female travelers. Female travelers also mentioned that they had a better perception in controlling behavior, receive more vaccines, and had higher compliance of malaria prophylaxis (Kwon et al., 2019; Lammert et al., 2017). Women were more motivated to conduct PTHC because they have awareness and anxiousness toward their health, do not adopt risky behavior, and men are not willing to attach with health information, which frequently correlates to masculinity (Chow et al., 2018; Ek, 2015). It implies that men and women have an equal position and an entitlement in accessing health facility and applying healthy behavior in their daily activity. Additionally, the globalization era has been leading the population to be interested in reading about health topics.

Moreover, nationality was not associated significantly with visits to the THC or seeking PTHC (Omer et al., 2015; Paudel et al., 2017), which showed a consistent result with this study. In addition, nationality was not significantly related with good or poor knowledge and attitude regarding travel health (Chow et al., 2018). Yet, other studies found that nationality was a predictor for travelers to visit the THC (Shady et al., 2015), lack of PTHC implementation seems more likely among immigrant travelers (Heywood et al., 2012).

Recently, every country has had an equal focus on addressing health problem-related communicable diseases, child and maternal health, and noncommunicable diseases (Doubova \& Pérez-Cuevas, 2018). This condition has pursued the availability and 
accessibility to reach a health facility, thus deliberating the number of health professionals is a requirement (Doubova \& Pérez-Cuevas, 2018). Green (1974) explained that availability and accessibility of resources and services are reinforcing factors that can influence individuals in applying health behavior. Health services such as promotion, preventive, curative, and rehabilitative will create a culture and belief in the community.

Furthermore, other analysis showed that most of the Asian travelers had good category of the PTHC behavior $(83,3 \%)$. It could be caused by the Asian travelers have already known infectious illnesses, including malaria, typhoid, hepatitis A and B, dengue, rabies, and Japanese encephalitis; therefore, it cannot be risks for Asian travelers who visit Asia countries (Piyaphanee et al., 2012). Travel medicine practice was developed with focus on travelers from Western countries (Europe, North America, Australia, and New Zealand) that will be travel to the developing with tropical and sub-tropical climate countries (Leder et al., 2017; Piyaphanee et al., 2012). Per capita income country, health program and service, and promotion program also affect PTHC seeking behavior among travelers (Heywood et al., 2012; Shady et al., 2015).

Although our study noted inconsistency with several studies that reported level of education was significantly correlated with travel-related health risks and vaccine acquisition (El-Ghitany et al., 2018; Zhang et al., 2016), Shady et al. (2015) supported our findings that education level was not significantly associated with PTHC implementation, preventive measurement, and non-compliance with malaria prophylaxis regimen.

It occurred due to various accessible resources of the information provided for travelers related to travel health or which described the destinations' condition, such as website (Heywood et al., 2012; Zuckerman et al., 2015). The low numbers of PTHC implementation was because travelers had lack of trust to the health providers, hence the health providers need to update their information based on the websites frequently visited by the travelers (Zuckerman et al., 2015). However, PTHC seeking needs to be conducted with the health provider to obtain suggestions that are adjusted with travelers' needs and avoid misconception to the information which has already been accessed (Heywood et al., 2012).

Further analysis showed that travelers with secondary and tertiary education had higher proportion of good category of the PTHC behavior. Travelers with higher education level have the capability to receive information easier and be able to utilize the information for disease prevention (Notoatmodjo, 2010). El-Ghitany et al. (2018) assumed that education provides better skills to deal with health risks. Clinically, education is still a factor which influences individual behavior.

A negative correlation not significantly associated between travel duration with PTHC behavior among international travelers in Badung, Bali was also demonstrated in our study, which implies that travelers with long-travel duration are more likely to have a poor behavior as compared with travelers with short-travel duration. Likewise, previous study had consistent findings with this study (Gautret et al., 2011). This finding shows that there are other factors which affect PTHC seeking behavior: travelers unwilling to seek health information through PTHC implementation due to they have traveled before to the same areas and have elicited of PTHC in previous travel (Shady et al., 2015). Lacking awareness among travelers toward health risk was noted in this study, even travelers with long-travel should seek PTHC because they might acquire higher health risk exposure.

It was inconsistent with further analysis, due to travelers with long-travel ( $>28$ days) dominated with poor category of the PTHC behavior (63.2\%). Our finding was also confirmed in previous study that reported travelers who lived more than four weeks in the destination country were rarely likely to seek health information to the THC (Shady et al., 2015). It shows, clinically, travel duration affects traveler visits to the THC and against health problems (Chow et al., 2018; Shady et al., 2015; Vilkman et al., 2016). The prolonged duration of trip is associated with the enhancement of health risk exposure and PTHC seeking (Pavli et al., 2014). For instance, among 15,180 travelers who visited to Kenya with average length of stay was 13.2 days, it increased the incidence of TD that attained 64 cases per 100 travelers (Leder et al., 2015).

Although types of the destination were not significantly correlated with PTHC behavior, a consistent finding was also found in our study, namely types of the destination was not associated with the acceptance of malaria chemoprophylaxis regimen (Stoney et al., 2016). Nevertheless, previous studies revealed that types of the destination correlated with the improvement of compliance to the anti-vector prevention (Kain et al., 2019), and visits to the THC (Shady et al., 2015). It shows that for the enhancement of travelers visiting to $t$ naturebased destinations, they should seek PTHC prior travel.

Most of the travelers have traveled to the naturebased destination (76.8\%) and are dominated by a good category of the PTHC behavior (55.2\%), although a poor behavior was also found in large proportion $(54.2 \%)$. The nature-based destination aims to provide a 'back to nature' concept with a wide range of travel experience. including adventure tourism, ecotourism, and rural tourism (Roxana, 2012). Travelers who visit to the nature-based destination received higher health hazards, such as travel-associated communicable diseases (Gautret et al., 2011).

Most of the travelers from Western countries that enrolled in this study spent their time on the beach to gain a tanned skin by doing sun bathing and surfing. Rawlings (2006) explained that Western countries travelers have type I and type II skin pigmentation, 
which implies both of those skin pigmentations are light pigmentation. The light pigmentation has fewer melanosomes, hence it could increase the sunburnt caused by UV light. The protection is vital to implement for travelers who visit to the tropical beach and sea by applying sun screen (Villard et al., 2017).

Moreover, there was a significant correlation between past-travel history to Bali with PTHC behavior among international travelers in Badung, Bali. Other studies also reported that travel history was associated with visits to the THC (Pavli et al., 2014; Shady et al., 2015), memory and knowledge after seeking PTHC (McGuinness et al., 2015). In contrast, previous studies mentioned that travel history was not a predictor for visiting THC (Liu et al., 2015), and knowledge regarding infectious diseases (Adou et al., 2019).

Further analysis described that the higher proportion of good category of the PTHC behavior was found among travelers without travel experience to Bali. It was showed a consistency with negative correlation in our study. Travelers who have traveled to Bali already knew the condition in Bali and had the confidence; in contrast, first-time travelers have alertness toward the health hazard related travel. Those conditions can affect their risk perception and unwillingness to comply with health recommendation (Shady et al., 2015).

This research has several limitations, including we were not able to reach out to all the tourist destinations mapped due to weather and uncertainty of the traveler's condition, thus we changed the target of the destination in Badung area. In addition, we did not identify PTHC implementation or seeking behavior and source of the information of PTHC among travelers prior the departure. We did not determine the time limit of past-travel history to Bali. Moreover, we had difficulty to accommodate travelers who visit a high mobility tourist destination.

\section{CONCLUSION}

To conclude this study, we found a significant and negative correlation between age and past-travel history to Bali with PTHC behavior among international travelers in Badung, Bali. Other variables such as sex, nationality, last education, travel duration, and types of the destination visited were not significantly associated with PTHC behavior. We recommend the travelers should uptake PTHC around six to eight weeks before departure. Nurses should be able to promote the implementation of PTHC to the target by heeding the age and past-travel history characteristics of the traveler because it can influence the compliance of travelers in implementing PTHC, thus nurses can develop an appropriate media promotion adjusted to the characteristics of travelers to persuade them to visit the THC. It also can be an opportunity for nurses to evolve their roles in the travel health sector as a care provider, educator, collaborator, case manager, and empower society to increase awareness toward health risk. Furthermore, we expected the government to consider our study while regulating the policy regarding PTHC implementation among international travelers as travel-related infectious disease prevention. A qualitative research needs to be conducted for exploring the factors related to travelers' awareness in implementing PTHC by addressing limitations and applying other health behavior theories.

\section{REFERENCES}

Adou, A.A., Napolitano, F., Vastola, A., Angelillo, I.F., 2019. Travelers' knowledge, attitudes, and behavior related to infectious diseases in Italy. PLOS ONE 14, e0215252. https://doi.org/10.1371/journal.pone.0215252

Al-Abri, S.S., Abdel-Hady, D.M., Al-Abaidani, I.S., 2016. Knowledge, attitudes, and practices regarding travel health among Muscat International Airport travelers in Oman: Identifying the gaps and addressing the challenges. J. Epidemiol. Glob. Health 6, 67-75. https://doi.org/10.1016/j.jegh.2016.02.003

Bali Government Tourism Office, 2019. Bali Tourism Statistic 2018. Bali Government Tourism Office, Denpasar.

Bauer, I., Hall, S., Sato, N., 2013. Providing travel health care - the nurses' role: An international comparison. Travel Med. Infect. Dis. 11, 214-224. https://doi.org/10.1016/j.tmaid.2013.04.004

Chinazzi, M., Davis, J.T., Ajelli, M., Gioannini, C., Litvinova, M., Merler, S., Piontti, A.P. y, Mu, K., Rossi, L., Sun, K., Viboud, C., Xiong, X., Yu, H., Halloran, M.E., Longini, I.M., Vespignani, A., 2020. The effect of travel restrictions on the spread of the 2019 novel coronavirus (COVID-19) outbreak. Science 368, 395-400. https://doi.org/10.1126/science.aba9757

Chow, Z.Y., Ching, S.M., Ramachandran, V., Hoo, F., Sulaiman, W.A.W., Foo, Y.L., Tey, Y.Y., Liong, C.W., Wen, L.H., Han, T.C., 2018. Travellers' knowledge, attitudes and practices regarding prevention of infectious diseases: A cross sectional study from Malaysian Airports. Southeast Asian J Trop Med Public Health 49, 707-716.

Del Prete, V., Mateo-Urdiales, A., Bueno-Cavanillas, A., Ferrara, P., 2019. Malaria prevention in the older traveller: a systematic review. J. Travel Med. 26. https://doi.org/10.1093/jtm/taz067

Djalante, R., Lassa, J., Setiamarga, D., Sudjatma, A., Indrawan, M., Haryanto, B., Mahfud, C., Sinapoy, M.S., Djalante, S., Rafliana, I., Gunawan, L.A., Surtiari, G.A.K., Warsilah, H., 2020. Review and analysis of current responses to COVID-19 in Indonesia: Period of January to March 2020. Prog. Disaster Sci. 6, 100091. https://doi.org/10.1016/j.pdisas.2020.100091

Doubova, S.V., Pérez-Cuevas, R., 2018. Going further to measure improvements in health-care access and quality. The Lancet 391, 2190-2192. 
https://doi.org/10.1016/S0140-6736(18)309875

Ek, S., 2015. Gender differences in health information behaviour: a Finnish population-based survey. Health Promot. Int. 30, 736-745. https://doi.org/10.1093/heapro/dat063

El-Ghitany, E.M., Abdelmohsen, M.A.M., Farghaly, A.G., Abd El-Gawwad, E.S., Abd El-Wahab, E.W., 2018. Travel health survey: Risk perception, healthseeking behavior, and subjective evaluation of travel health services in Egypt. Int. J. Travel Med. Glob. Health 6, 16-24. https://doi.org/10.15171/ijtmgh.2018.04

Gagneux-Brunon, A., Andrillat, C., Fouilloux, P., Daoud, F., Defontaine, C., Charles, R., Lucht, F., BotelhoNevers, E., 2016. Pre-travel advice seeking from GPs by travellers with chronic illness seen at a travel clinic. J. Travel Med. 23, taw013. https://doi.org/10.1093/jtm/taw013

Gautret, P., Tantawichien, T., Hai, V.V., Piyaphanee, W., 2011. Determinants of pre-exposure rabies vaccination among foreign backpackers in Bangkok, Thailand. Vaccine 29, 3931-3934. https://doi.org/10.1016/j.vaccine.2011.03.096

Green, L.W., 1974. Toward cost-benefit evaluations of health education: some concepts, methods, and examples. Health Educ. Monogr. 2, 34-64. https://doi.org/10.1177/10901981740020S106

Heywood, A.E., Watkins, R.E., Iamsirithaworn, S., Nilvarangkul, K., MacIntyre, C.R., 2012. A crosssectional study of pre-travel health-seeking practices among travelers departing Sydney and Bangkok airports. BMC Public Health 12, 321. https://doi.org/10.1186/1471-2458-12-321

Kain, D., Findlater, A., Lightfoot, D., Maxim, T., Kraemer, M.U.G., Brady, O.J., Watts, A., Khan, K., Bogoch, I.I., 2019. Factors affecting pre-travel health seeking behaviour and adherence to pretravel health advice: A systematic review. J. Travel Med. 26, 1-14. https://doi.org/10.1093/jtm/taz059

Kwon, H.Y., Lee, H., Im, J.H., Park, S.-G., Lee, Y.J., Baek, J.H., Lee, J.-S., 2019. Determinants of compliance of travelers with vaccination and malaria prophylaxis at a travel clinic. J. Korean Med. Sci. 34, e217. https://doi.org/10.3346/jkms.2019.34.e217

Lammert, S.M., Rao, S.R., Jentes, E.S., Fairley, J.K., Erskine, S., Walker, A.T., Hagmann, S.H., Sotir, M.J., Ryan, E.T., LaRocque, R.C., 2017. Refusal of recommended travel-related vaccines among U.S. international travellers in Global TravEpiNet. J. Travel Med. https://doi.org/10.1093/jtm/taw075

Leder, K., Borwein, S., Chanthavanich, P., Chatterjee, S., Htun, K., Marma, A.S.P., Nakatani, I., Ok, J.-J., Pakasi, L., Pandey, P., Piyaphanee, W., Rupali, P., Schwartz, E., Shinozuka, T., Phu, P.T.H., Watanabe, H., Visser, J., Wilder-Smith, A., Zhang, M., McGuinness, S.L., 2017. Travel medicine perspectives of select travel medicine experts practicing in the Asia-Pacific region. J. Travel Med. 24. https://doi.org/10.1093/jtm/tax012

Leder, K., Steffen, R., Cramer, J.P., Greenaway, C., 2015. Risk assessment in travel medicine: how to obtain, interpret, and use risk data for informing pretravel advice. J. Travel Med. 22, 13-20. https://doi.org/10.1111/jtm.12170

Liu, S.J., Sharapov, U., Klevens, M., 2015. Patient awareness of need for hepatitis A vaccination (prophylaxis) before international travel. J. Travel Med. 22, 174-178. https://doi.org/10.1111/jtm.12186

Masyeni, S., Yohan, B., Somia, I.K.A., Myint, K.S.A., Sasmono, R.T., 2018. Dengue infection in international travellers visiting Bali, Indonesia. J. Travel Med. 25, 1-7. https://doi.org/10.1093/jtm/tay061

McGuinness, S.L., Spelman, T., Johnson, D.F., Leder, K., 2015. Immediate recall of health issues discussed during a pre-travel consultation. J. Travel Med. 22, 145-151. https://doi.org/10.1111/jtm.12183

Notoatmodjo, S., 2010. Ilmu Perilaku Kesehatan. Rineka Cipta, Jakarta.

Omer, F., Hassan, N., Hussain, H., Mana, S., Awad, O., 2015. Travel health, gaps in knowledge, attitudes, and practices among Dubai travellers, Dubai, UAE. Int. J. Prev. Med. Res. 1, 126-131.

Paudel, P., Raina, C., Zwar, N., Seale, H., Worth, H., Sheikh, M., Heywood, A.E., 2017. Risk activities and pre-travel health seeking practices of notified cases of imported infectious diseases in Australia. J. Travel Med. 24. https://doi.org/10.1093/jtm/tax044

Pavli, A., Silvestros, C., Patrinos, S., Lymperi, I., Maltezou, H.C., 2014. Pre-travel preparation practices among business travellers to tropical and subtropical destinations: Results from the Athens International Airport Survey. Travel Med. Infect. Dis. 12, 364-369. https://doi.org/10.1016/j.tmaid.2013.12.004

Piyaphanee, W., Steffen, R., Shlim, D.R., Gherardin, T., Chatterjee, S., 2012. Travel medicine for Asian travelers-do we need new approaches? J. Travel Med. 19, 335-337. https://doi.org/10.1111/j.17088305.2012.00661.x

Potter, P.A., Perry, A.G., 2005. Buku ajar fundamental keperawatan: Konsep, proses, dan praktik, 4 th ed. EGC, Jakarta.

Rawlings, A.V., 2006. Ethnic skin types: are there differences in skin structure and function?1. Int. J. Cosmet. Sci. 28, 79-93. https://doi.org/10.1111/j.14672494.2006.00302.x

Roxana, D.M., 2012. Considerations about ecotourism and nature-based tourism - realities and perspectives. Int. J. Acad. Res. Econ. Manag. Sci. 1, 215-221.

Shady, I., Gaafer, M., Bassiony, L., 2015. Travel risk behaviors as a determinants of receiving pretravel health consultation and prevention. Trop. 
Dis. Travel Med. Vaccines 1. https://doi.org/10.1186/s40794-015-0003-8

Sohail, A., McGuinness, S.L., Lightowler, R., Leder, K., Jomon, B., Bain, C.A., Peleg, A.Y., 2019. Spectrum of illness among returned Australian travellers from Bali, Indonesia: a 5-year retrospective observational study. Intern. Med. J. 49, 34-40. https://doi.org/10.1111/imj.13993

Stoney, R.J., Chen, L.H., Jentes, E.S., Wilson, M.E., Han, P.V., Benoit, C.M., MacLeod, W.B., Hamer, D.H., Barnett, E.D., 2016. Malaria prevention strategies: Adherence among Boston area travelers visiting malaria-endemic countries. Am. J. Trop. Med. Hyg. 94, 136-142. https://doi.org/10.4269/ajtmh.150565

Sumadewi, K.T., Eka, P.A., Masyeni, S., Rusni, N.W., Witari, N.P.D., 2018. Utilization review inpatient and outpatient of traveller related to thypoid in Bali (study in two regencies: a case report), in: IOP Conference Series: Materials Science and Engineering. Presented at the 3rd Annual Applied Science and Engineering Conference (AASEC 2018), IOP Publishing, Bandung. https://doi.org/10.1088/1757899X/434/1/012335

Swedarma, K.E., Yanti, L.P.E., Sulistiowati, N.M.D., 2016. Nursing role in supporting the development of community based on health tourism in Bali. J. INJEC 1 , 15-18.
Tan, E.M., St. Sauver, J.L., Sia, I.G., 2018. Impact of pretravel consultation on clinical management and outcomes of travelers' diarrhea: a retrospective cohort study. Trop. Dis. Travel Med. Vaccines 4, 16. https://doi.org/10.1186/s40794-018-0076-2

Vilkman, K., Pakkanen, S.H., Lääveri, T., Siikamäki, H., Kantele, A., 2016. Travelers' health problems and behavior: prospective study with post-travel follow-up. BMC Infect. Dis. 16, 328. https://doi.org/10.1186/s12879-016-1682-0

Villard, M., Bonini, J., Criquet-Hayot, A., Baubion, E., Derancourt, C., 2017. Kite-surfers' sun risk in the tropics. J. Travel Med. 24. https://doi.org/10.1093/jtm/taw079

World Health Organization, 2020. Gender [WWW Document]. Gender. URL https://www.who.int/westernpacific/healthtopics/detail/gender (accessed 3.20.20).

Zhang, Min, Zhang, J., Hao, Y., Fan, Z., Li, L., Li, Y., Ju, W., Zhang, H., Liu, W., Zhang, Mengzhang, Wu, D., He, H., 2016. Vaccination knowledge, attitude and practice among Chinese travelers who visit travel clinics in Preparation for international travel. J. Travel Med. 23, taw051. https://doi.org/10.1093/jtm/taw051

Zuckerman, J.N., Brunette, G.W., Leggat, P.A., 2015. Essential Travel Medicine, 1st ed. Wiley Blackwell, West Susex. https://doi.org/10.24990/injec.v1i1.101 